\title{
Anxiety Severity Levels and Coping Strategies during the COVID-19 Pandemic among People Aged 15 Years and Above in Gonabad, Iran
}

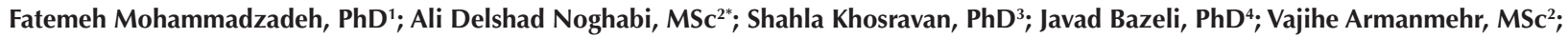 \\ Toktam Paykani, PhD ${ }^{2}$

\begin{abstract}
'Department of Epidemiology \& Biostatistics, School of Health, Social Development \& Health Promotion Research Center, Gonabad University of Medical Sciences, Gonabad, Iran

${ }^{2}$ Social Development \& Health Promotion Research Center, Gonabad University of Medical Sciences, Gonabad, Iran

${ }^{3}$ Department of Community Health Nursing \& Nursing Management, School of Nursing, Social Determinants of Health Research Center, Gonabad University of Medical Sciences, Gonabad, Iran

${ }^{4}$ Department of Medical Emergencies, School of Nursing, Social Development \& Health Promotion Research Center, Gonabad University of Medical Sciences, Gonabad, Iran
\end{abstract}

\begin{abstract}
Background: The coronavirus disease 2019 (COVID-19) outbreak is a global health problem. It is necessary to provide evidence on its unprecedented psychological effects to develop effective psychological interventions. The current study aims to determine the anxiety severity level, coping strategies, and influencing factors in response to the COVID-19 pandemic among people aged 15 years and above in Gonabad, Iran.

Methods: We conducted a cross-sectional survey via online questionnaires between February and March 2020. We evaluated the anxiety severity levels and coping strategies using the Corona Disease Anxiety Scale (CDAS) and Coping Inventory for Stressful Situations-Short Form (CISS-SF), respectively. Multinomial and ordinal logistic regression models were used to identify the predictors of coping strategies and anxiety.

Results: Totally, 500 people completed the questionnaires (response rate: $73 \%$ ). Of them, $53.4 \%$ (95\% confidence interval [CI]: 48.9\%-57.8\%) suffered moderate to severe levels of anxiety. More than half of the respondents (52.0\%; $95 \% \mathrm{Cl}: 47.5 \%-56.4 \%$ ) utilized emotional-based or avoidant coping strategies. People with no academic education (odds ratio [OR]: $2.16 ; 95 \%$ Cl: 1.41 3.31) and without physical exercise (OR: 2.04; 95\% Cl: 1.22-3.33) preferred emotional-based coping instead of problem-based coping strategy. Female gender (OR: 1.60, 95\%, Cl: 1.13-2.28), underlying medical conditions (OR: 2.52, 95\% Cl: 1.65-3.87), and emotional-based coping (OR: 4.06, 95\% Cl: 2.76-5.99) were associated with higher severity levels of anxiety.

Conclusion: The severity of anxiety during the COVID-19 pandemic was significant among participants. Further attention is needed to enhance the mental health of the vulnerable population during the COVID-19 pandemic. Our findings also identified some factors related to the severity level of anxiety related to COVID-19 that could help formulate better psychological interventions. Keywords: Anxiety, COVID-19, Iran, Pandemics, Psychological adaptation

Cite this article as: Mohammadzadeh F, Delshad Noghabi A, Khosravan S, Bazeli J, Armanmehr V, Paykani T. Anxiety severity levels and coping strategies during the COVID-19 pandemic among people aged 15 years and above in Gonabad, Iran. Arch Iran Med. 2020;23(9):633-638. doi: 10.34172/aim.2020.76.
\end{abstract}

Received: April 17, 2020, Accepted: June 29, 2020, ePublished: September 1, 2020

\section{Introduction}

On December 31, 2019, a new infectious disease appeared in Wuhan, Hubei province, China, which is believed to have originated from a seafood market. It is known as the coronavirus disease 2019 (COVID-19) and is caused by a new SARS-Cov-2 virus. ${ }^{1,2}$ COVID-19 is a complex disease with an incubation period of 2-14 days. ${ }^{3}$ Most COVID-19 patients suffer from the main symptoms, including fever, fatigue, and dry cough. Nasal obstruction, nasal discharge, sore throat, abdominal discomfort, vomiting, abdominal pain, and diarrhea are also other symptoms of COVID-19, which may occur in some cases. ${ }^{4}$ However, it may also be asymptomatic in some people. ${ }^{5,6}$ Older people and those with underlying medical problems are at higher risk of developing severe COVID-19.7 On March 12, 2020, due to the rapid increase in the number of confirmed cases outside China, the COVID-19 outbreak was announced as a pandemic by the World Health Organization (WHO). ${ }^{8}$ Reports indicate that the number of confirmed cases and fatalities of COVID-19 has been higher than the other outbreaks caused by coronaviruses, including SARS and MERS. ${ }^{9}$ At the time of writing, 200 countries and territories across the world have been affected by the disease, ${ }^{10}$ and the USA, China, Italy, Spain, Germany, and Iran are among the top ranks of COVID-19 cases. ${ }^{11}$ The COVID-19 pandemic is a serious threat to humankind, 
which affects all aspects of human life, including physical, mental, social, and economic well-being. Currently, the nature of COVID-19 is unknown and ambiguous. There is limited control over it and it has no specific treatments or vaccines. Thus, it may be accompanied by overwhelming emotional responses, such as stress and anxiety.

Anxiety is a physiological response to an ambiguous and pervasive threat, ${ }^{12}$ and a certain amount of it is beneficial in keeping people alert and motivated about protective behaviors to prevent the spread of COVID-19. However, extreme levels of anxiety are disruptive. In general, there are three strategies for coping with stressful situations: problem-focused coping, concentrating on the problem and attempting to overcome stressors; emotional-focused coping, adjusting emotional reactions to stressors; and avoidance coping, trying to deny or ignore stressors. ${ }^{13}$ Anxiety level and coping strategies correlated with the outbreak of COVID-19 may vary for different individuals in different communities. Epidemiological data on mental health issues concerned with COVID-19 could help us to learn how best to react to challenges during the outbreak, and design effective psychological interventions.

The current study aims to determine the anxiety level, coping strategies, and influencing factors in response to pandemic COVID-19 in an Iranian population.

\section{Materials and Methods}

Study Design, Participants, and Procedure

This cross-sectional study was performed between February and March 2020 on people aged 15 years and above in Gonabad, Khorasan Razavi, Iran. Gonabad is second in terms of the number of the elderly population in Iran. ${ }^{14}$ As a consequence, a significant population is at an increased risk of severe COVID-19. In this study, subjects were selected by way of convenience sampling. We sent a link of the web page of the electronic questionnaires to people via SMS, WhatsApp, and Telegram, inviting them to take part in the study. The inclusion criteria were as follows: 1) 15 years of age or above; 2) willingness to participate in the study; 3) no recent hospitalization due to acute respiratory infection or COVID-19, for the respondents or their family; 4) no history of recent sudden death in the family. The minimum sample size, using a power analysis by taking into account a small effect size of 0.2 , a power of $99 \%$ and a confidence interval of $95 \%$, was estimated to be 460 individuals. We increased the sample size to 506 individuals by taking a possible attrition rate of $10 \%$.

\section{Demographic Characteristics}

The demographic questionnaire included several items about age, gender, marital status, educational level, underlying medical conditions (diabetes, heart disease, cancer, kidney disease, or chronic lung disease), smoking cigarette or hookah, and exercising.
Corona Disease Anxiety Scale (CDAS)

The CDAS was developed by Alipour et al ${ }^{15}$ to assess the anxiety level concerning the COVID-19 epidemic. They evaluated the validity and reliability of the scale in an Iranian sample. The validity of the questionnaire included content, construct, convergence, and criterion validity. The reliability was assessed using Guttman's lambda and Cronbach's alpha: $\lambda=0.922$, and $\alpha=0.919$. The final version of this tool has 18 items and includes two components of psychological symptoms (items 1 to 9) and physical symptoms (items 10 to 18). The tool is rated on a 4-point Likert scale (never $=0$, sometimes $=1$, most often $=2$, and always $=3$ ); thus, the scores range from 0 to 54 . Higher scores in this questionnaire indicate a higher level of anxiety in individuals. The scores of 0-16, 17-29, and 30-54 are considered as mild, moderate, and severe anxiety levels, respectively. ${ }^{15}$ In the current study, the reliability of the scale was assessed using the Cronbach's alpha which was 0.94 .

Coping Inventory for Stressful Situations-Short Form (CISS-SF)

The CISS was developed by Endler and Parker to determine strategies for coping with stressful situations. ${ }^{16}$ The short form of CISS is composed of 21 items that measure three different coping strategies, namely problem-based coping, emotional-based coping, and avoidant coping. Each coping strategy contains 7 items rated on a 5-point Likert scale from 1 ("not at all") to 5 ("so much"). An individual's coping strategy is determined based on their highest score of the three strategies. The validity and reliability of the scale have been assessed and confirmed in Iran. ${ }^{17}$ In this study, reliability of the scale was assessed using Cronbach's alpha: $\alpha=0.94$.

\section{Statistical Analysis}

Data analyses were done using R version 3.5.0. Continuous variables were summarized as means \pm standard deviations (SD). Descriptive statistics for categorical variables were also described using frequencies and percentages. Simple analyses were performed using the multinomial logistic regression and ordinal logistic regression models. A cutoff of $P<0.2$ was considered for entering variables to multivariable analysis. The multivariable analysis was conducted using multinomial logistic regression and ordinal logistic regression. The statistical significance was considered as $P<0.05$.

\section{Results}

Demographic Characteristics and Preventive Behaviors during COVID-19

Data of 500 people were collected and analyzed (response rate: $73 \%$ ). The characteristics of the participants are shown in Table 1. The mean age of participants was $37.6 \pm$ 12.7 years, ranging from 15 to 78 years. Among them, 14 
$(2.8 \%)$ stated that they had undergone a laboratory test of COVID-19, due to having symptoms. Also, 170 (34.0\%) had either traveled or had visitors from other places during the outbreak of COVID-19. Moreover, 272 (54.4\%) stated that they strictly implemented hygienic measures such as washing hands with soap and water and avoiding touching their face; $105(21.0 \%)$ of them always kept a distance of two meters from other people; 203 (40.6\%) attempted to observing complete home quarantine.

\section{Anxiety Level during the COVID-19 Outbreak}

Table 1 shows the anxiety severity levels of the participants during the CPVID-19 outbreak. The mean overall anxiety, physical anxiety symptoms, and psychological anxiety symptoms were $18.6 \pm 10.8,5.2 \pm 5.4$, and $13.5 \pm$ 6.2 , respectively, based on the CDAS scores. Our findings showed that $36.4 \%(95 \%$ confidence interval [CI]: $32.1 \%-40.7 \%)$ of the participants had moderate levels, and $17.0 \%$ (95\% CI: $13.8 \%-20.6 \%)$ had severe levels of anxiety. These values were $49.0 \%$ (95\% CI: $44.5 \%-$ $53.47 \%$ ) and $18.4 \%$ (95\% CI: $15.1 \%-22.1 \%)$ for the physical symptoms, and 73.2\% (95\% CI: 69.1\%-77.0\%) and $17.0 \%$ (95\% CI: $13.8 \%-20.6 \%)$ for the psychological symptoms, respectively.

\section{Coping Strategies during the COVID-19 Outbreak}

The dominant coping strategy was problem-focused (48.0\%; 95\% CI: 43.5\%-52.5\%). Also, 182 (36.4\%; 95\% CI: $32.2 \%-40.8 \%)$ used the emotional-focused, and 78 (15.6\%; 95\% CI: $12.5 \%-19.1 \%)$ used the avoidant coping strategy. Gender, educational level, smoking, and exercising were independent variables with $P$ values $<0.20$ in simple multinomial logistic regression (Table 2). The results of the multivariable multinomial logistic regression showed that people with no academic education were 2.16 (95\% CI: 1.41-3.31) times more likely to use an emotional-based coping strategy instead of problem-based coping. These people were also 2.03 (95\% CI: 1.17-3.54) times more likely to use the avoidant coping strategy instead of problem-based coping. Furthermore, the odds of utilizing the emotional coping strategy instead of problem-based coping in those who exercised were 0.49fold smaller than those who did not (Table 2).

Relationship between Anxiety Level and Individual Characteristics and Coping Strategies during the COVID-19 Outbreak

The results of multivariable ordinal logistic regression showed that emotional-based coping, underlying medical conditions, and gender had a statistically significant relationship with anxiety level during the COVID-19 outbreak, after adjusting for other demographic variables. The odds of suffering higher severity levels of anxiety for those who used the emotional-based coping were approximately 4 times more than those who used problembased coping (odds ratio [OR]: 4.06, 95\% CI: 2.76-5.99). Individuals with underlying medical conditions were also more likely to have higher severity levels of anxiety (OR: 2.52, 95\% CI: 1.65-3.87). In addition, females experienced higher severity levels of anxiety compared to males (OR: 1.60, 95\%, CI: 1.13-2.28). We found no significant relationship between marital status and anxiety severity levels $(P>0.05)$. The bold-faced values in Table 3 indicate statistically significant results.

Table 1. Characteristics of the Study Participants by the Anxiety Severity Level during the COVID-19 Outbreak

\begin{tabular}{|c|c|c|c|c|}
\hline \multirow{2}{*}{ Characteristics } & \multicolumn{3}{|c|}{ Anxiety Severity Level (Based on CDAS) } & \multirow{2}{*}{ P Value* } \\
\hline & Mild & Moderate & Severe & \\
\hline Age $(y)$, mean \pm SD & $37.2 \pm 11.6$ & $37.7 \pm 13.6$ & $38.7 \pm 13.4$ & 0.386 \\
\hline \multicolumn{4}{|l|}{ Gender, n (\%) } & \multirow{3}{*}{0.143} \\
\hline Female & $124(44.9)$ & $96(34.8)$ & $56(20.3)$ & \\
\hline Male & $109(48.7)$ & $86(38.4)$ & $29(12.9)$ & \\
\hline \multicolumn{4}{|l|}{ Educational level, n (\%) } & \multirow{3}{*}{$<0.001$} \\
\hline High school or less & $55(31.1)$ & $81(45.8)$ & $41(23.2)$ & \\
\hline College & $178(55.1)$ & $101(31.3)$ & $44(13.6)$ & \\
\hline \multicolumn{4}{|l|}{ Marital status, n (\%) } & \multirow{3}{*}{0.214} \\
\hline Married & $181(45.8)$ & $140(35.4)$ & $74(18.7)$ & \\
\hline Single /divorced/ widowed & $52(49.5)$ & $42(40.0)$ & $11(10.5)$ & \\
\hline \multicolumn{4}{|c|}{ Underlying medical condition, $\mathrm{n}(\%)$} & \multirow{3}{*}{$<0.001$} \\
\hline Yes & $32(32.7)$ & $36(36.7)$ & $30(30.6)$ & \\
\hline No & $201(50.0)$ & $146(36.3)$ & $55(13.7)$ & \\
\hline \multicolumn{4}{|l|}{ Smoking cigarettes/hookah, n (\%) } & \multirow{3}{*}{0.910} \\
\hline Yes & $26(45.6)$ & $23(40.4)$ & $8(14.0)$ & \\
\hline No & $207(46.7)$ & $159(35.9)$ & $77(17.4)$ & \\
\hline \multicolumn{4}{|l|}{ Physical exercise, n (\%) } & \multirow{3}{*}{0.012} \\
\hline Yes & 67 (54.9) & $43(35.2)$ & $12(9.8)$ & \\
\hline No & $166(43.9)$ & 139 (36.8) & $73(19.3)$ & \\
\hline
\end{tabular}

SD, standard deviation.

*P value based on simple ordinal logistic regression model. 
Table 2. Associated Risk Factors for Coping Strategy using the Multinomial Logistic Regression Model

\begin{tabular}{|c|c|c|c|c|}
\hline \multirow{4}{*}{ Characteristics } & \multicolumn{4}{|c|}{ Coping Strategy** } \\
\hline & \multicolumn{2}{|c|}{ Category 1 (Emotional-Based Coping) } & \multicolumn{2}{|c|}{ Category 2 (Avoidant-Based Coping) } \\
\hline & Simple & Multivariable & Simple & Multivariable \\
\hline & OR $(95 \% \mathrm{CI})$ & OR $(95 \% \mathrm{Cl})$ & OR $(95 \% \mathrm{CI})$ & OR $(95 \% \mathrm{CI})$ \\
\hline Age (y) & $0.99(0.98,1.01)$ & - & $1.00(0.99,1.03)$ & - \\
\hline \multicolumn{5}{|l|}{ Gender } \\
\hline Female & $0.61(0.41,0.89)^{*}$ & $0.69(0.45,1.05)$ & $0.67(0.40,1.11)^{*}$ & $0.77(0.45,1.33)$ \\
\hline Male & 1 & 1 & 1 & 1 \\
\hline \multicolumn{5}{|l|}{ Educational level } \\
\hline High school or less & $2.52(1.67,3.80)^{*}$ & $2.16(1.41,3.31)$ & $2.04(1.19,3.49)^{*}$ & $2.03(1.17,3.54)$ \\
\hline College & 1 & 1 & 1 & 1 \\
\hline \multicolumn{5}{|l|}{ Marital status } \\
\hline Married & $1.05(0.53,2.09)$ & - & $1.42(0.74,2.73)$ & - \\
\hline Single/divorced/ widowed & 1 & - & 1 & - \\
\hline \multicolumn{5}{|c|}{ Underlying medical condition } \\
\hline Yes & $1.11(0.68,1.80)$ & - & $1.12(0.59,2.12)$ & - \\
\hline No & 1 & - & 1 & - \\
\hline \multicolumn{5}{|l|}{ Smoking cigarettes/hookah } \\
\hline Yes & $2.12(1.14,3.92)^{*}$ & $1.36(0.69,2.68)$ & $1.71(0.76,3.86)^{*}$ & $1.30(0.55,3.09)$ \\
\hline No & 1 & 1 & 1 & 1 \\
\hline \multicolumn{5}{|l|}{ Physical Exercise } \\
\hline Yes & $0.45(0.28,0.74)^{*}$ & $0.49(0.30,0.82)$ & $1.45(0.84,2.49)^{*}$ & $1.57(0.90,2.73)$ \\
\hline No & 1 & 1 & 1 & 1 \\
\hline
\end{tabular}

$\mathrm{OR}$, odds ratio; $\mathrm{Cl}$, confidence interval.

$* P<0.2 ; * *$ Reference category: Problem-based coping

\section{Discussion}

COVID-19 is an infectious disease over which people and governments have little control. It has an increasing growth in the world, and there is currently no treatment or vaccine for it. Therefore, in addition to the physical problems it poses to the affected person, it may also be accompanied by high psychological pressure on all people and lead to uncontrolled emotional responses, such as anxiety and stress. Epidemiological data are required to help understand the circumstances and respond best to the challenges of the outbreak of COVID-19. The

Table 3. Associated Risk Factors for Anxiety Severity Level during the COVID-19 Outbreak

\begin{tabular}{lc}
\hline Predictors & $\begin{array}{c}\text { Multivariable Ordinal Logistic } \\
\text { Regression Analysis } \\
\text { OR } \mathbf{( 9 5 \%} \mathbf{~ C l})\end{array}$ \\
\hline $\begin{array}{l}\text { Gender } \\
\text { Female } \\
\text { Male }\end{array}$ & $1.60(1.13,2.28)$ \\
Marital status & 1 \\
Married & $0.93(0.01,1.42)$ \\
Single/divorced/widowed & 1 \\
Underlying medical condition & \\
Yes & $2.52(1.65,3.87)$ \\
No & 1 \\
Coping strategy & \\
Emotional-based & \\
Avoidant & \\
Problem-based & $0.93(0.01,1.42)$ \\
\hline OR odds ratio; $\mathrm{Cl}$, confidence interval & 1 \\
\hline
\end{tabular}

$\mathrm{OR}$, odds ratio; $\mathrm{Cl}$, confidence interval. current study aimed to determine the anxiety level, coping strategies, and influencing factors in response to COVID-19 pandemic in Gonabad, Iran.

According to the results of the present study, the prevalence of anxiety during the COVID-19 pandemic was $53.4 \%$ (95\% CI: $48.9 \%-57.8 \%$ ), of which $36.4 \%$ (95\% CI: 32.1\%-40.7\%) was moderate, and 17.0\% (95\% CI: $13.8 \%-20.6 \%)$ was severe. This rate was far higher than the rates reported among general Iranian populations $(4.7 \%-21.9 \%),{ }^{18-20}$ or global estimate of the prevalence of anxiety (3.6\%). ${ }^{21}$ It was also much higher than the anxiety prevalence during the COVID-19 pandemic in the general population of China $(28.8 \%) .{ }^{22}$ Gonabad is second in terms of the number of the elderly population in Iran, and a significant population is at an increased risk of severe COVID-19, which can induce anxiety in individuals and their families. A portion of the difference in the prevalence rate can also be due to the difference in measurement instruments.

The findings of the study showed that more than half of the participants $(52.0 \%)$ used emotional-based coping and avoidant coping strategies during the COVID-19 outbreak. It indicates that a large number of participants feel powerless to handle the stressful situation of the COVID-19 pandemic. Problem-based coping is typically used following the feeling of control over stressful situations. In contrast, emotional-based coping, or avoidant coping is the product of believing in uncontrollable stressors and 
compulsion to endure stressful events. ${ }^{23,24}$ We also found that people with higher educational levels and those who performed physical exercise tended to use problem-based coping instead of other forms of coping strategies. These findings support the findings of previous researches. ${ }^{25,26} \mathrm{~A}$ higher educational level is typically associated with a higher level of intellectual function and a broader spectrum of coping strategies that can contribute to better coping and well-being-based behaviors. ${ }^{27,28}$ Also, individuals with physical exercise are more likely to have positive thoughts and a relaxed mind to cope with stressful events. Therefore, they are more concentrated on solving the problems rather than attempting to distract, blame, discharge, ignore, or avoid. ${ }^{26,29}$

In the current study, people with emotional-based coping suffered higher severity levels of anxiety during the COVID-19 outbreak than those who used the problembased coping strategy. Taha et $\mathrm{al}^{30}$ also observed a similar finding in an examination of the H1N1 pandemic. Some other studies have also shown that emotional-based coping is associated with negative consequences such as stress and anxiety, whereas problem-based coping is inversely related to these symptoms. ${ }^{31,32}$ We also observed that individuals with underlying medical conditions suffer higher levels of anxiety that supports the hypothesis of co-occurrence of underlying medical conditions with psychiatric disorders, including mood disorders. ${ }^{33,34}$ On the other hand, the evidence suggests that people with underlying medical conditions have a higher risk of more severe COVID-19, which can lead to higher levels of anxiety in these people. ${ }^{7}$

We observed that females experienced higher severity levels of anxiety compared to males, which was consistent with common patterns in the general population in Iran and other countries. ${ }^{20,35,36}$ Genetics and female sex hormones, along with environmental factors, may play a role in raising the vulnerability of women to stressors. ${ }^{37,38}$

To our knowledge, this is the first study to assess anxiety levels and coping strategies during the COVID-19 pandemic among an Iranian population. In addition, the use of standardized questionnaires, in particular, the use of the CDAS instead of general anxiety questionnaires, was the strength of this research.

There were also some limitations to this study. First, the design of this study was cross-sectional, and so causal relationships could not be assessed. Second, we conducted a web-based survey to avoid possible infections with COVID-19. Therefore, the sampling strategy was nonrandom, and subjects participated voluntarily in the study, which may lead to selection bias and poor generalizability. Third, self-reported questionnaires might be another source of bias in this study.

In conclusion, more than half of the respondents experienced mild to severe anxiety and utilized emotionalbased or avoidant coping strategies during the initial phase of the COVID-19 pandemic. Those with higher education levels and physical exercise preferred to utilize problembased coping instead of other types of coping strategies. People with female gender, underlying medical conditions, and those who use emotional-based coping are more likely to experience higher severity levels of anxiety.

\section{Authors' Contribution}

FM: analysis, interpretation and drafting. A.DN: data acquisition. FM, A.DN, Sh.K, JB, VA and TP: contributed to the design, concepts of the work, revising the draft, approval of the final version of the manuscript, and agreed for all aspects of the work.

\section{Conflict of Interest Disclosures}

There are no conflicts of interest.

\section{Ethical Statement}

The study was approved by the Ethics Committee of Gonabad University of Medical Sciences (Ethical code No: IR.GMU. REC.1398.188). At the beginning of the online questionnaire, the necessary details of the research and its objectives were presented, and all participants filled out the online questionnaires anonymously.

\section{Acknowledgements}

The current study was approved (approval No: A-10-1283-3) and financially supported by the Social Development \& Health Promotion Research Center, Gonabad University of Medical Sciences, Gonabad, Iran. The authors gratefully acknowledge all the people who participated in the study.

\section{References}

1. World Health Organization. Coronavirus disease (COVID-2019) situation report-1. 21 JANUARY 2020. Available from: https://www.who.int/docs/default-source/ coronaviruse/situation-reports/20200121-sitrep-1-2019-ncov. pdf?sfvrsn=20a99c10_4.

2. Liu CY, Yang YZ, Zhang XM, Xu X, Dou QL, Zhang WW, et al. The prevalence and influencing factors for anxiety in medical workers fighting COVID-19 in China: A cross-sectional survey. Epidemiol Infect. 2020;148:e98. doi:10.2139/ssrn.3548781.

3. Lai CC, Shih TP, Ko WC, Tang HJ, Hsueh PR. Severe acute respiratory syndrome coronavirus 2 (SARS-CoV-2) and corona virus disease-2019 (COVID-19): the epidemic and the challenges. Int J Antimicrob Agents. 2020;55(3):1-9. doi: 10.1016/j.ijantimicag.2020.105924.

4. Lu Q, Shi Y. Coronavirus disease (COVID-19) and neonate: What neonatologist need to know. J MedVirol. 2020;92(6):5647. doi: $10.1002 / j m v .25740$.

5. Li Q, Guan X, Wu P, Wang X, Zhou L, Tong Y, et al. Early transmission dynamics in Wuhan, China, of novel coronavirusinfected pneumonia. N Engl J Med. 2020;382(13):1199-207. doi: 10.1056/NEJMoa2001316.

6. Zhu N, Zhang D, Wang W, Li X, Yang B, Song J, et al. A novel coronavirus from patients with pneumonia in China, 2019. N Engl J Med. 2020;382(8):727-33. doi: 10.1056/ NEJMoa2001017.

7. World Health Organization. Coronavirus disease (COVID-2019) situation report - 51. 11 March 2020. Available from: https://www.who.int/docs/default-source/ coronaviruse/situation-reports/20200311-sitrep-51-covid-19. pdf?sfvrsn=1 ba62e57_10.

8. World Health Organization. WHO announces COVID-19 outbreak a pandemic. 2020. Available from: http://www.euro. who.int/en/health-topics/health-emergencies/coronaviruscovid-19/news/news/2020/3/who-announces-covid-19outbreak-a-pandemic. Accessed March 2020.

9. Poon LL, Peiris M. Emergence of a novel human coronavirus threatening human health. Nat Med. 2020;26(3):317-9. doi: 
10.1038/s41591-020-0796-5

10. World Health Organization. Coronavirus disease (COVID-19) Pandemic. 2020. Available from: https://www.who.int/ emergencies/diseases/novel-coronavirus-2019. Accessed March 2020.

11. World Health Organization. Coronavirus disease (COVID-2019) situation report - 66. 26 March 2020. Available from: https://www.who.int/docs/default-source/ coronaviruse/situation-reports/20200326-sitrep-66-covid-19. pdf?sfvrsn=9e5b8b48_2.

12. Peter $\mathrm{E}, \mathrm{Bot} \mathrm{H}$. Containing anxiety in the wake of the $\mathrm{H} 1 \mathrm{H} 1$ influenza pandemic: Documents as sedative agents. Nurs Inq. 2009;16(4):273-4. doi: 10.1111/j.1440-1800.2009.00477.x.

13. Folkman S. Personal control and stress and coping processes: A theoretical analysis. J Pers Soc Psychol. 1984;46(4):839-52. doi: 10.1037/0022-3514.46.4.839.

14. Khosravan S, Alaviani M, Alami A, Tavakolizadeh J. Epidemiology of loneliness in elderly women. JRH. 2014;4(4):871-7.

15. Alipour A, Ghadami A, Alipour Z, Abdollahzadeh $\mathrm{H}$. Preliminary validation of the Corona Disease Anxiety Scale (CDAS) in the Iranian sample. Quarterly Journal of Health Psychology. 2020;8(4):163-75.

16. Endler NS, Parker JDA. Multidimensional assessment of coping: A critical evaluation. J Pers Soc Psychol. 1990;58(5):844-54. doi: 10.1037//0022-3514.58.5.844.

17. Shokri O, Taghilou S, Geravand F, Paeizi M, Moulaei M, abd Elahpour $M$, et al. Factor structure and psychometric properties of the farsi version of the coping inventory for stressful situations (CISS). Advances in Cognitive Sciences. 2008;10(3):22-33.

18. Ahmadvand A, Sepehrmanesh Z, Ghoreishi FS, Afshinmajd S. Prevalence of psychiatric disorders in the general population of Kashan, Iran. Arch Iran Med. 2012;15(4):205-9.

19. Mirzaei M, Ardekani SMY, Mirzaei M, Dehghani A. Prevalence of depression, anxiety and stress among adult population: results of yazd health study. Iran J Psychiatry. 2019;14(2):13746.

20. Hajebi A, Motevalian SA, Rahimi-Movaghar A, Sharifi V, AminEsmaeili M, Radgoodarzi R, et al. Major anxiety disorders in Iran: prevalence, sociodemographic correlates and service utilization. BMC Psychiatry. 2018;18(1):261. doi: 10.1186/ s12888-018-1828-2.

21. World Health Organization. Depression and other common mental disorders: global health estimates. 2017. Available from: http://apps.who.int/iris/bitstream/10665/254610/1/ WHO-MSD-MER-2017.2-eng.pdf?ua=1. Accessed March 2020.

22. Wang C, Pan R, Wan X, Tan Y, Xu L, Ho CS, et al. Immediate psychological responses and associated factors during the initial stage of the 2019 coronavirus disease (COVID-19) epidemic among the general population in china. Int J Environ Res Public Health. 2020;17(5):1729. doi: 10.3390/ ijerph17051729.

23. Ramezanli S, Koshkaki AR, Talebizadeh M, Jahromi ZB, Jahromi MK. A study of the coping strategies used by nurses working in the intensive care units of hospitals affiliated to
Jahrom University of Medical Sciences. Int J Curr Microbiol Appl Sci. 2015;4(4):157-63.

24. Kurimay D, Pope-Rhodius A, Kondric M. The relationship between stress and coping in table tennis. J Hum Kinet. 2017:55:75-81. doi: 10.1515/hukin-2017-0007.

25. Leite FM, Amorim MH, Castro DS, Primo CC. Coping strategies and the relationship with sociodemographic conditions of women with breast cancer. Acta Paul Enferm. 2012;25(2):211 7. doi: 10.1590/S0103-21002012000200009.

26. Kim JH, McKenzie LA. The impacts of physical exercise on stress coping and well-being in university students in the context of leisure. Health. 2014;6(19):2570-80. doi: 10.4236/ health.2014.619296

27. Nowak Z, Wańkowicz Z, Laudanski K. Denial defense mechanism in dialyzed patients. Med Sci Monit. 2015; 21:1798-805. doi: 10.12659/MSM.893331.

28. Baharom N, Hassan MR, Ali N, Shah SA. Improvement of quality of life following 6 months of methadone maintenance therapy in Malaysia. Subst Abuse Treat Prev Policy. 2012;7:32. doi:10.1186/1747-597X-7-32.

29. Azizi M. Effects of doing physical exercises on stress-coping strategies and the intensity of the stress experienced by university students in Zabol, Southeastern Iran. Procedia Soc Behav Sci. 2011;30:372-5. doi: 10.1016/j.sbspro.2011.10.073

30. Taha S, Matheson K, Cronin T, Anisman H. Intolerance of uncertainty, appraisals, coping, and anxiety: The case of the 2009 H1N1 pandemic. Br J Health Psychol. 2014;19(3):592605. doi: 10.1111/bjhp.12058.

31. Ben-Zur H. Coping styles and affect. Int J Stress Manag. 2009; 16(2):87-101. doi: 10.1037/a0015731.

32. Keramati $M$, Ebrahimi $H$, Basirinezhad $M$, Shamsizadeh $M$, Mohammadpourhodki R. The prevalence of anxiety, stress, and depression with respect to coping strategies in caregivers of patients with head injuries. Arch Trauma Res. 2019;8(3):1659. doi: 10.4103/atr.atr_35_19.

33. Kariuki-Nyuthe C, Stein DJ. Anxiety and related disorders and physical illness. Karger: Basel; 2015. doi: 10.1159/000365538.

34. Scott KM, Bruffaerts R, Tsang A, Ormel J, Alonso J, Angermeyer MC, et al. Depression-anxiety relationships with chronic physical conditions: results from the World Mental Health Surveys. J Affect Disord. 2007;103(1-3):113-20. doi: 10.1016/j.jad.2007.01.015

35. Kessler RC, Chiu WT, Demler O, Walters EE. Prevalence, severity, and comorbidity of 12-month DSM-IV disorders in the National Comorbidity Survey Replication. Arch Gen Psychiatry. 2005;62(6):617-27. doi: 10.1001/archpsyc.62.6.617.

36. Bandelow B, Michaelis S. Epidemiology of anxiety disorders in the 21st century. Dialogues Clin Neurosci. 2015;17(3):32735 .

37. Kendler KS, Walters EE, Neale MC, Kessler RC, Heath AC, Eaves LJ. The structure of the genetic and environmental risk factors for six major psychiatric disorders in women: Phobia, generalized anxiety disorder, panic disorder, bulimia, major depression, and alcoholism. Arch Gen Psychiatry. 1995;52(5):374-83. doi: 10.1001/archpsyc.1995.03950170048007.

38. Redmond G. Mood disorders in the female patient. Int J Fertil Womens Med. 1997;42(2):67-72. 